\title{
MODELING OF VISCOELASTIC BEHAVIOR OF 3D Printed Polimeric Materials
}

\author{
J. Ibrulj, M. Obucina \& E. Dzaferovic
}
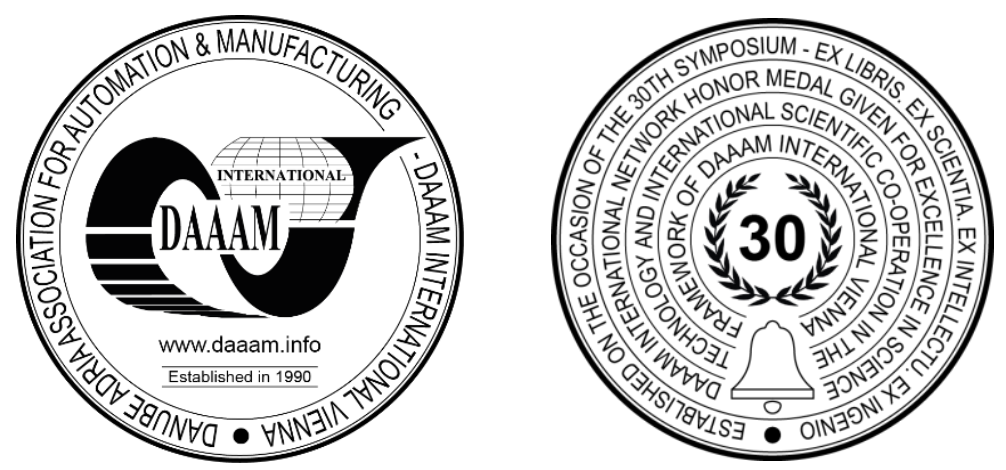

This Publication has to be referred as: Ibrulj, J[usuf]; Obucina, M[urco] \& Dzaferovic, E[jub] (2020). Modeling of Viscoelastic Behavior of 3D Printed Polimeric Materials, Proceedings of the 31st DAAAM International Symposium, pp.0328-0333, B. Katalinic (Ed.), Published by DAAAM International, ISBN 978-3-902734-29-7, ISSN 1726-9679, Vienna, Austria

DOI: $10.2507 / 31$ st.daaam.proceedings.046

\begin{abstract}
Linear viscoelastic materials whose characteristics are suitable for description by the Prony series use experimental data to obtain the so-called "master" curve. The analysis of experimental results with the Prony model sometimes requires prior knowledge of the time parameters of the model $\square$,, in order to make the corresponding module more suitable for use in analytical form. In this way, the existing model is optimized to some extent, while in this paper the approach is used that all parameters in the Prony series for $\left(\mathrm{E}_{\mathrm{i}}, \tau_{\mathrm{i}}\right)$ were determined using the well-known least squares method and its variations. The number of members in Prony's series is initially smaller and increases proportionately. To determine the relaxation modulus using the Prony model, an example from an available article [1] was selected in this paper, while the performed experiment was used to determine the creep modulus. During the performance of the load experiment, the function of constant increase (ramp-test) was used. The previous experiment was done for the actual material ABS plastic (Acrylonitrile butaden styrene).
\end{abstract}

Keywords: Viscoelasticity; Shift-factor; Relaxation; ABS plastic; 3D printing.

\section{Introduction}

Most polymeric materials are used today for good mechanical properties in relation to manufacturing costs. For this reason, the mechanical properties of these materials are very interesting also because of their wide application. In the last 30 years, it is important to know the dependence of deformation $(\varepsilon)$ and stress $(\sigma)$ for the analysis of the stability of elements or products exposed to load. It is known that the characteristics of polymeric materials change over time. A complete description of the mechanical properties of polymeric materials usually requires knowledge of the behavior of the material over 10,15, or 20 time decades [1]. This means that to determine the reliability and durability of a particular polymer structure, it is necessary to know the mechanical characteristics throughout the time of use. In the theory of linear viscoelasticity, such characteristics are most often the relaxation modulus $E(t)$ and the creep function $J(t)$, which define the response of the material to the applied load (eg the Heaviside function). Also, due to the shortening of the experiment, it is often necessary to replace the step load function with other non-standard loads, such as a ramp function or a function that has a constant stress-strain ratio [2].

Viscoelastic behavior of materials is a function of time and temperature. Generally, this dependence requires the definition of a set of principal curves at different temperatures that fully characterize the material under all possible operating conditions. 
These major curves can be obtained experimentally [3] or by viscoelastic interconversions [4] and [5]. In any case, the experimental data must be fitted to a viscoelastic model, e.g. Prony series [6], to perform further calculations with viscoelastic material. With this condition, there are several major methods, such as procedure $\mathrm{X}$ [7], [8], collocation method [9], multi-data method [10], or the Emri and Tschoegl iterative algorithm [11] used to derive the coefficients viscoelastic model. The aim of this study is to determine the relaxation modulus in analytical form using the Prony series based on experimental results. To meet this goal, we will use the well-known least squares method and its variations, as well as the MATLAB software with built-in subroutines. After such a relaxation module, further research is possible on the application of the analytical expression in the numerical method of finite volumes, which is a proposal for some future research.

In this paper, a method of approximating viscoelastic experimental functions, such as the relaxation modulus is used, including the possibility of inhomogeneous distribution of discrete times. In addition, 3D printing uses raw material efficiently, resulting in very low or zero waste [12]. Reducing the amount of waste material is particularly important from an environmental point of view. During the layer-by-layer process, the material undergoes physical and thermal changes concerning its mechanical properties. Using mechanical analysis and simple relaxation, it is possible to determine how the dynamic properties of the material change depending on the process parameters and how such parameters affect the mechanical properties [13].

In dynamic - mechanical analysis, the stress value varies periodically, usually a sinusoidal change in the angular frequency applied to the sample is used [14]. From the response to the applied mechanical loading of the specimen, information such as the stiffness of the material can be obtained. The deformation obtained by periodic varying stresses will also be periodic but shifted by a given value of the phase angle due to the dissipation of energy in the form of heat. In dynamic mechanical tests, the stiffness of a material is measured over time. The strength of the sample depends on the modulus of elasticity of the material. The modulus of elasticity is defined as the ratio of the stress and strain values resulting from the applied force.

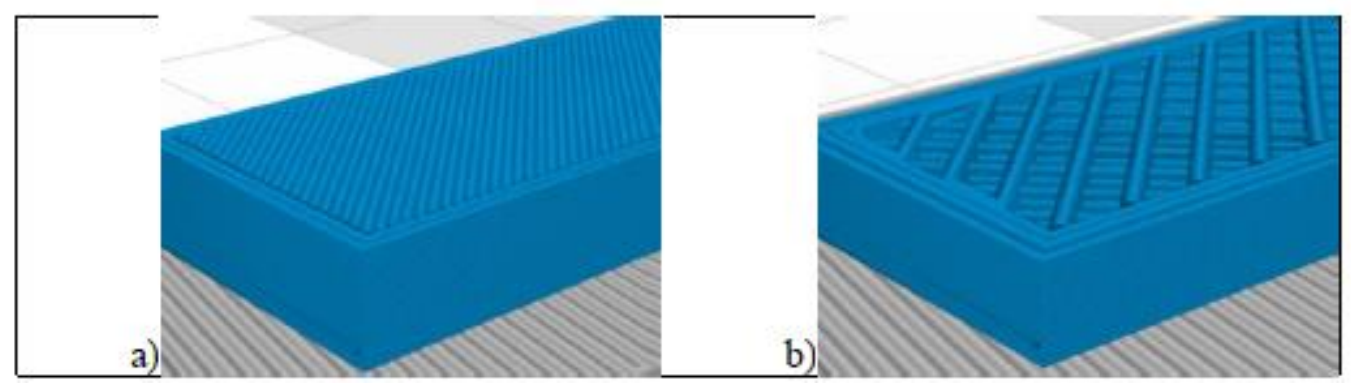

Fig. 1. Specimens obtained by 3D printing. a) Surface with 3 layers b) Inside structures.

The ARES-G2 TA instrument with accessories was used for the study (Fig. 2). The specimens are attached to a rectangular torsion fixture. The test procedure is controlled by computer and Trios software.

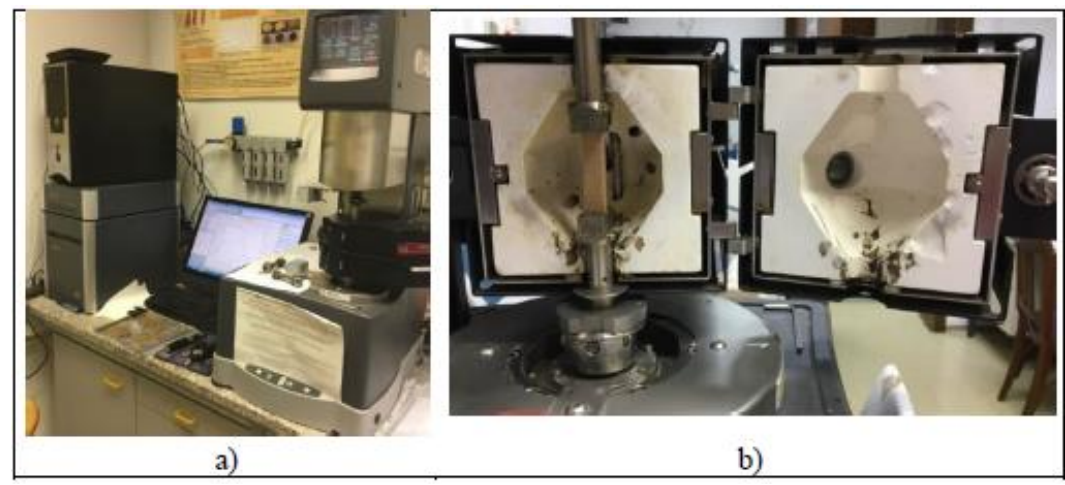

Fig. 2. a) Rheometer ARES G2, b) Specimen fixed and prepared.

Viscoelastic materials can be easily understood as materials whose properties lie somewhere between an elastic solid and Newtonian fluid. Although its features are generally more complex, these settings make it easier understanding of viscoelastic mathematical models for these types of materials. The resilient solid is represented by a spring while Newton's fluid is represented by a slider, in other words viscoelastic materials can be represented by combinations of springs and sliders. The simplest the models are Maxwell and Kelvin Model, where the former is used (with elements in a row) to represent relaxing viscoelastic functions, $\mathrm{E}(\mathrm{t})$, while the other (with elements in parallel) is used to represent viscoelastic creep functions D (t) [15], [16] and [17]. 
In the Prony series, each member of the series identifies with a single Maxwell element or in the case of a creep function with a single Kelvin element. The prony series for the generalized Maxwell model is [18] and [19]:

$$
E(t)=E_{\infty}+\sum_{m=1}^{M} E_{m} \cdot \exp \left(-\frac{t}{\tau_{m}}\right)
$$

Where is: $\mathrm{E}_{\infty}, \mathrm{E}_{\mathrm{m}}, \tau_{\mathrm{m}}$ so-called. „rubbery“ relaxation modulus, coefficients of Prony serries and relaxation times respectively. While for Kelvin's model accordingly serrie is:

$$
D(t)=D_{o}+\sum_{m=1}^{M} D_{m}\left[1-\exp \left(-t / \rho_{m}\right)\right]
$$

Where is: $D_{o}, D_{m}, \rho_{m}$ coefficients for Prony's serries respectively in case of creep compliance.

\section{Examples of application}

\subsection{Relaxation modulus determination}

The data from the available paper [20] were taken to determine the relaxation modulus and the algorithm described above was used and results are presented graphically in the following figures.

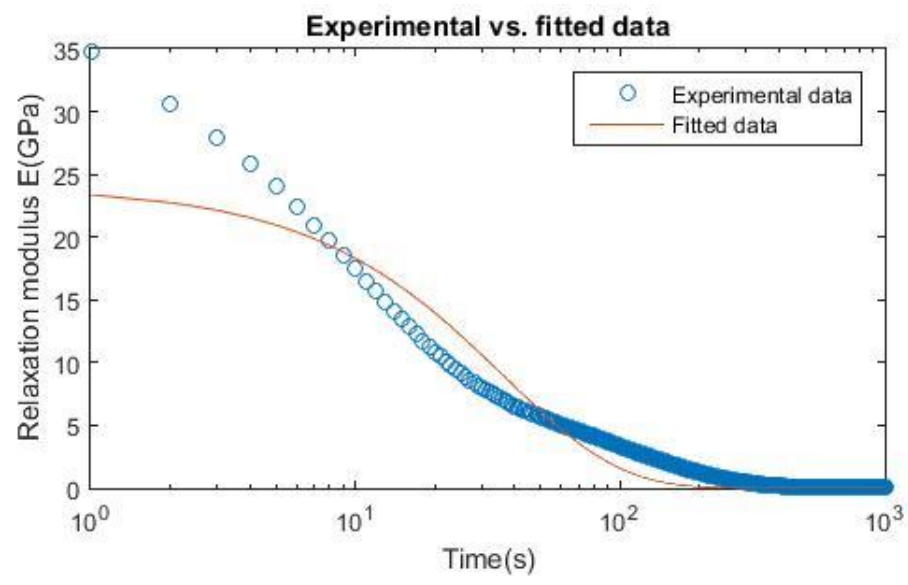

Fig. 3. Approximation of the relaxation modulus with 3 parameters $(1$ member in the Prony series and one free member).

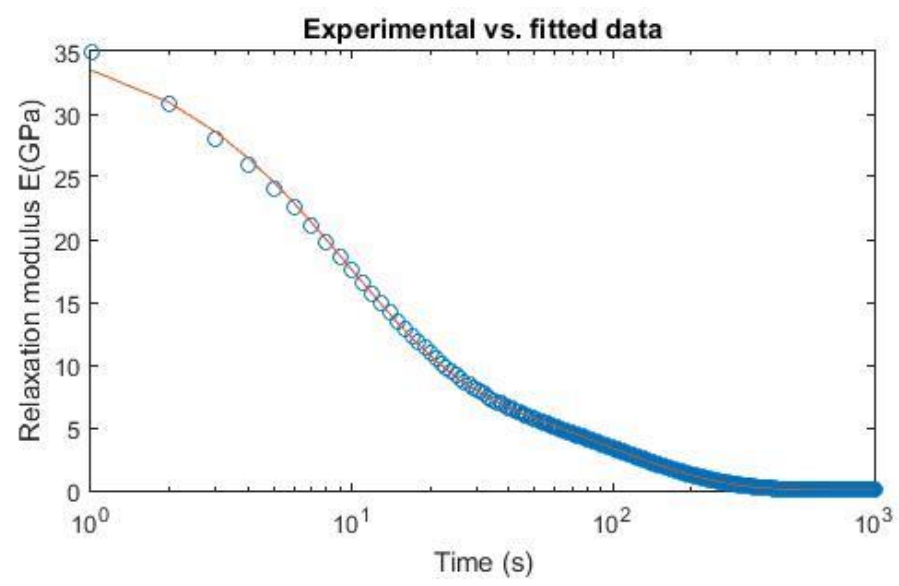

Fig. 4. Approximation of the relaxation module with 5 parameters ( 2 members in the Prony series and one free member). 


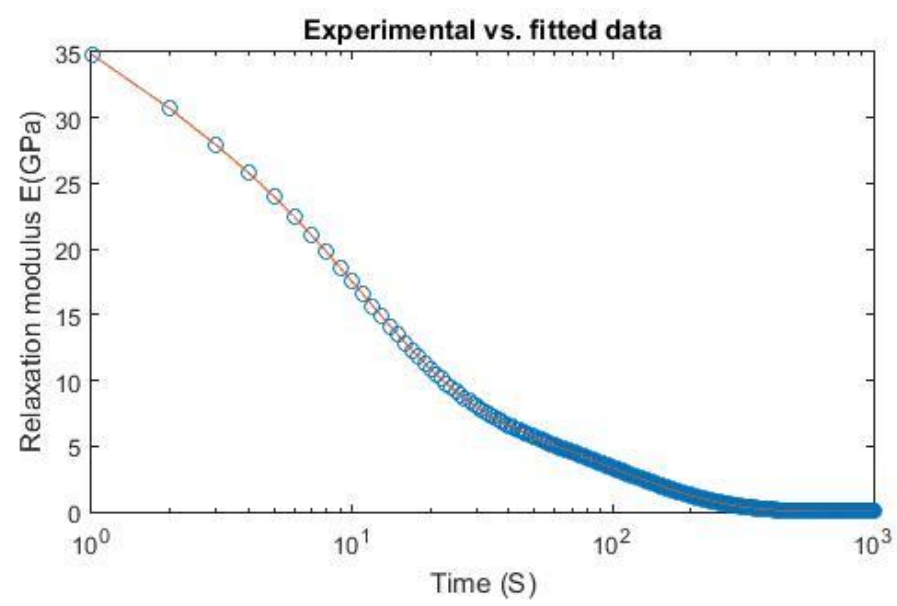

Fig. 5. Approximation of the relaxation modulus with 7 parameters ( 3 members in the Prony series and one free member).

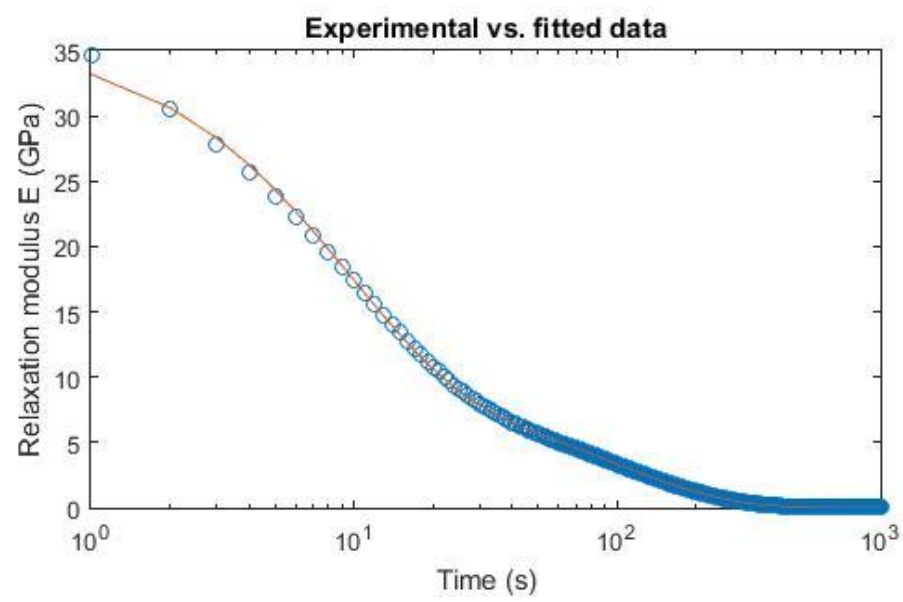

Fig. 6. Approximation of the relaxation module with 9 parameters (4 members in the Prony series and one free member).

The previous pictures show that with the increase in the number of members in the Prony series there is a better match between the experimental and the "fit" results. When we have a smaller number of members in the Prony series, the waviness of the approximation curve as in Figure 3 is pronounced, whereas with the increase in the number of members this waviness disappears (Figure 6). Values for individual members in the Prony series are given in next table. Table 1 shows the schedule of relaxation times in such a way that when we have enough members in the Prony series, each time decade has its own relaxation time. This phenomenon is most noticeable in the 4-member series, which results in a slight undulation of the curve in the study domain, while in a smaller number of members, the undulation is expressed because the relaxation times are distributed sporadically by decades.

\begin{tabular}{|c|c|c|c|c|c|c|c|c|}
\hline \multicolumn{9}{|c|}{ Optimised coefficients of Prony serries } \\
\hline & \multicolumn{2}{|c|}{$\mathbf{1}$ terms } & \multicolumn{2}{c|}{$\mathbf{2}$ terms } & \multicolumn{2}{c|}{3 terms } & \multicolumn{2}{c|}{$\mathbf{4}$ terms } \\
\hline $\mathbf{i}$ & $\mathbf{E}_{\mathbf{i}}$ & $\boldsymbol{\tau}_{\mathbf{i}}$ & $\mathbf{E}_{\mathbf{i}}$ & $\boldsymbol{\tau}_{\mathbf{i}}$ & $\mathbf{E}_{\mathbf{i}}$ & $\boldsymbol{\tau}_{\mathbf{i}}$ & $\mathbf{E}_{\mathbf{i}}$ & $\boldsymbol{\tau}_{\mathbf{i}}$ \\
\hline 0 & $2.7 \mathrm{E}-03$ & & $3.2 \mathrm{E}-05$ & & $3.0 \mathrm{E}-06$ & & $3.1 \mathrm{E}-05$ & \\
\hline 1 & $2.4 \mathrm{E}+01$ & $3.7 \mathrm{E}+01$ & $9.4 \mathrm{E}+00$ & $9.8 \mathrm{E}+01$ & $8.1 \mathrm{E}+00$ & $1.0 \mathrm{E}+00$ & $2.7 \mathrm{E}+01$ & $9.2 \mathrm{E}+00$ \\
\hline 2 & & & $2.7 \mathrm{E}+01$ & $9.2 \mathrm{E}+00$ & $9.1 \mathrm{E}+00$ & $1.0 \mathrm{E}+02$ & $1.9 \mathrm{E}+00$ & $2.2 \mathrm{E}-14$ \\
\hline 3 & & & & & $2.5 \mathrm{E}+01$ & $1.0 \mathrm{E}+01$ & $9.3 \mathrm{E}+00$ & $9.8 \mathrm{E}+01$ \\
\hline 4 & & & & & & & $7.5 \mathrm{E}-01$ & $2.1 \mathrm{E}-03$ \\
\hline
\end{tabular}

Table 1. Coefficients in Prony's serries. 
In the case of an analysis of the deviations of the approximated and experimental results, it is expected that with the increase in the number of Prony members the approximation error will decrease.

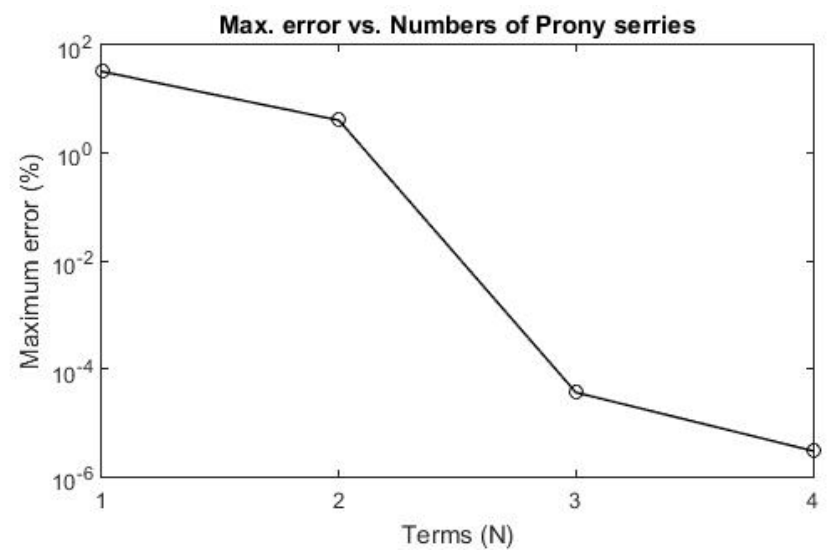

Fig. 7. Maximum deviation of the optimized values in the Prony series with respect to the experimental results.

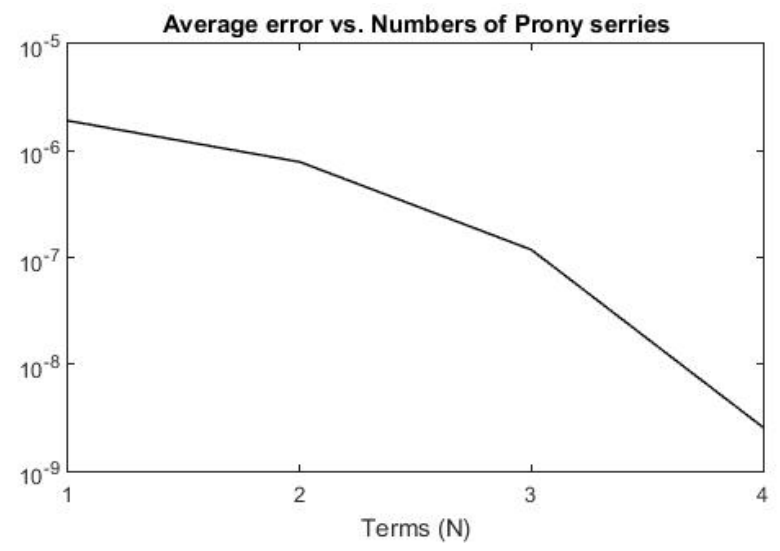

Fig. 8. Average deviation of the optimized values in the Prony series with respect to the experimental results.

For this example, an analysis of the maximum and average deviation of the approximation curve from the experimental results was performed. The results depending on the number of parameters and the approximation error values are presented in Figures 7 and 8. From the presented results for the average and maximum deviation of the experimental and approximate results, it is evident that with the increase in the number of members in the series, we also have the decrease of the experimental error, which is expected. However, if we exceed a certain number of members in the series with which we want to approximate the results, the value of the maximum and mean deviation of the experimental and approximate results will again increase. This all indicates that there is some optimal number of members in the series that should be used for approximation.

\section{Conclusion}

Calculations of relaxation modules based on experimental results in the form of analytical expression included an individual approach of the researchers. This would mean that different researchers get different analytical expressions based on the same data. This paper describes a methodology for determining relaxation modulus based on experimental results in the form of a Prony series. The choice of Prony's series has an advantage in its exponential expression, which enables more efficient use of computer memory in numerical procedures. A well-known least squares method and its variation applied to experimental data were used to determine the coefficients in the Prony series. The example of determining these functions in mathematical form in this study showed that this methodology can be successfully used to obtain analytical expressions of relaxation modules. The fit results correspond to a good agreement with the experimentally obtained results, as well as a decrease in the relative deviation with an increase in the number of members in the Prony series. Research in this paper is limited to the determination of analytical expressions, ie the determination of coefficients in the Prony series. Further research can be extended to the use of such expressions in the numerical procedure, such as the finite volume method, to calculate total stresses and strains. 


\section{References}

[1] Emri, I. \& Gergesova M. (2010). Time-dependent Behaviour of Solid Polimers, Encyclopedia of Life Support Systems, Rheology, pp. 247-330, EOLLS Publisher/UNESCO

[2] Saprunov, I.; Gergesova, M. \& Emri, I. (2013). Mechanics of Time-Dependent Materials, Vol. 18, Issue 2, pp. 349372

[3] Fernández, P.; Lamela-Rey, M. J.; Fernández-Canteli, A.; García-Barruetabeńa, J. \& Cortés, F. (2011). VI International Materials Symposium, Guimarăes, Portugal, pp. 149

[4] Park, S. W. \& Schapery, R.A. (1999). Methods of Interconversion Between Linear Viscoelastic Material Functions, Part I - A Numerical Method based on Prony Series, International Journal of Solids and Structures, Vol. 36, pp. 1653-1675

[5] Emri, I.; Von Bernstorff, B. S.; Cvelbar, R. \& A. Nikonov. (2005). Journal Non-Newton Fluid Mech., Vol. 129, pp.75

[6] Chen, T. (2000). Determining a Prony Series for a Viscoelastic Material from Time Varying Strain Data, NASA/TM2000, ARL-TR-2206

[7] Tobolsky, A. V. (1956). Stress Relaxation Studies of the Viscoelastic Properties of Polymers, Journal of Applied Physics, Vol. 27, pp. 673

[8] Tobolsky, A. V. (1960). Properties and Structures of Polymers, Wiley and Sons, pp. 186

[9] Schapery, R.A. (1962). Proc. 4th US National Congress Appl. Mech. Vol. 2, pp. 1075

[10] Cost, T.L. \& Becker, E.B. (1970). International Journal of Numeric Methods in Engineering, Vol. 2, pp. 207

[11] Emri, I. \& Tschoegl, N.W. (1993). Rheol. Acta, Vol 32, pp. 311

[12] Wimmer, R.; Steyrer, B.; Woes, J.; Koddenberg, T. \& Mundigler, N. (2015). 3D Printing and Wood, Pro-Ligno, Vol. 11, pp. 144-149

[13] Arivazhagan, A. \& Masood, S. H. (2012). Dynamic Mechanical Properties of ABS Material Processed by Fused Deposition Modelling, International Journal of Engineering Research and Applications (IJERA), Vol. 2, pp. 20092014

[14] Obucina, M.; Dzaferović, E.; Ibrulj, J.; Cekic, A.; Kuzman, K.M.; Kariz, M. \& Sernek, M. (2018). Analysis of the Viscoelastic Properties of Polymeric Materials used for 3D Printing, DAAM international scientific book, pp. 083096, Chapter 08

[15] Ferry, J.D. (1980). Viscoelastic Properties of Polymers, 3rd. ed., Wiley

[16] Alwis, K. G. N. C.; Burgoyne, C. J. (2006). Time-Temperature Superposition to Determine the Stress-Rupture of Aramid Fibers, Appl. Compos. Mater. Vol. 13, pp. 249-264

[17] Mun, S; Chehab, G. R. \& Kim, Y. R. (2007). Determination of Time-Domain Viscoelastic Functions using Optimized Interconversion Techniques, Road Materials and Pavement Design

[18] Dzaferovic, E.; Ivankovic, A. \& Demirdzic, I. (2000). Finite Volume Modelling of Linear Viscoelastic Deformation, 3rd International Congress of Croatian Society of Mechanics, Cavtat, Croatia, pp. 245-253

[19] Ibrulj, J.; Dzaferovic, E. \& Obucina, M. (2020). Determination of Relaxation and Creep Modulus of Polymer Materials Obtained by 3D Printing, New Technologies, Development and Application III, pp.256-266

[20] Babaei, B.; Davarian, A.; M.Pryse K.; Elson, E. L. \& Genin G. M. (2015). Efficient and Optimized Identification of Generalized Maxwell Viscoelastic Relaxation Spectra, Journal of the Mechanical Behavior of Biomedical Materials pp. $32-41$. 